\title{
PREVALENCE OF POSTNATAL DEPRESSION AND ASSOCIATED FACTORS AMONG HIV- POSITIVE WOMEN IN PRIMARY CARE IN NKANGALA DISTRICT, SOUTH AFRICA
}

\author{
K Peltzer ${ }^{1,2}, P h D, D r$ Habil \\ M E Shikwane ${ }^{1}$, MA (Psych) \\ ${ }^{1}$ HIV/AIDS/STI and TB (HAST), Human Sciences Research Council, Pretoria \\ ${ }^{2}$ Department of Psychology, University of Limpopo, Turfloop
}

Background. The prevalence of postpartum depression in South Africa is high, but there is lack of prevalence data on postnatal depression among HIV-infected women.

Aim. The aim of this study was to determine the prevalence of depressed mood and associated factors in postnatal HIV-positive women in primary care facilities in Nkangala district, Mpumalanga, South Africa.

Methods. This cross-sectional study was carried out on 607 HIV-positive postnatal women in 48 primary health care clinics and community health centres in Nkangala district. Postnatal women were recruited by systematic sampling (every consecutive patient over a period of 2 months). Demographic and other data were obtained from all the women who responded to a questionnaire in the local language on male involvement, HIV test disclosure, delivery and infant profile, infant HIV diagnosis, stigma, discrimination, postnatal depression, attendance of support groups and social support.

Results. Overall, $45.1 \%$ of women reported a depressed mood in the postnatal period. Depressed mood in a multivariable analysis was significantly associated with internalised stigma (odds ratio $(O R) 1.12,95 \%$ confidence interval (Cl) $1.05-1.19 ; p=0.000$ ), discrimination experiences (OR 1.22, $\mathrm{Cl} 1.03-1.46 ; p=0.023$ ), lack of social support (OR 0.86, Cl $0.74-0.99 ; p=0.037$ ) and having had an STI in the past 12 months (OR 2.22, Cl $1.21-4.04$; $p=0.010$ ). There were no statistically significant correlations between the Edinburgh Postnatal Depression Scale (EPDS) scores of the women and age, marital status, level of education, employment status and number of own children.

Conclusion. Depressed mood is common among HIV-positive postpartum women. This is significantly associated with lack of social support, stigma and discrimination. Routine screening to identify those currently depressed or at risk of depression should be integrated into postnatal care settings to target those most needing intervention.

Postnatal depression is the most frequently recognised mental disorder after delivery and generally begins within 4 - 6 weeks after childbirth. ${ }^{1}$ The symptoms include low mood, tiredness, insomnia, lack of energy, forgetfulness, irritability and poor functioning. The occurrence of depressive illness after childbirth can be detrimental to the mother, her marital relationship and her children and can have adverse long-term effects if not treated. ${ }^{2}$ In addition, maternal postpartum depression poses significant risks for mother-child interaction and long-term infant outcomes. ${ }^{2}$

Although the prevalence of postpartum depression in South Africa is high (34.7\%), there are few studies on the prevalence of postnatal depression among HIV-infected women. ${ }^{3}$ The postpartum period is a time in which women are more vulnerable to depressive symptoms, ${ }^{4}$ but most studies have only focused on depressive symptoms in HIV-positive individuals in general. In a study conducted in an urban setting in South Africa, maternal postpartum depression was measured using the Edinburgh Postnatal Depression Scale (EPDS) among 83 HIV-infected mother infant dyads and $42.2 \%$ of the women scored above the cut-off point for depression. ${ }^{5}$ HIV-infected mothers are at high risk for a range of emotional and psychiatric problems that may impact on immunity and HIV disease progression. ${ }^{4,6-8}$

Preterm delivery ${ }^{9}$ and difficulties with partners $^{10}$ have been found to be associated with postpartum depression. In addition, low levels of social support, particularly partner support and availability of people to depend on during the pregnancy and early postpartum, and a woman's relationship with her own parents were 
found to be significant factors for both antenatal and postnatal depression. ${ }^{11}$ Society expects women to be mothers, and yet at the same time it negatively judges HIV-positive women who choose to become pregnant. ${ }^{12}$ Emotional support plays a role in depressive symptoms; with limited support, HIV-positive individuals are more likely to exhibit depressive symptoms. ${ }^{13,14}$

The present study aimed to determine the prevalence of depressed mood and associated factors in postnatal HIV-positive women in primary care facilities in Nkangala district, Mpumalanga, South Africa.

\section{METHOD \\ STUDY SETTING}

The study was conducted in Nkangala district, Mpumalanga, which is ranked the third most rural province in South Africa, with $60.9 \%$ of its population living in rural areas. ${ }^{15} \mathrm{Nkangala}$ district had a population of 1121839 people in $2008 / 9$. At $28.4 \%$, the unemployment rate is higher than the national unemployment rate $(25.3 \%)$. More than a quarter $(28.6 \%)$ of households in Nkangala earned less than R30 000 per year (R2 500 per month) in $2009 .{ }^{15}$ It was estimated that $90 \%$ of the population was dependent on the state for the provision of all their health services. ${ }^{16}$ The primary health care utilisation rate of 2.2 visits per person per year has been constant from 2008 to $2009 .{ }^{17}$ The antenatal HIV prevalence rate in Nkangala district was $32.5 \%$ in 2009. ${ }^{18}$

\section{SAMPLE AND PROCEDURE}

The sample included 607 postnatal HIV-positive women with an infant aged 1 - 10 weeks $(30.8 \%)$, 11 weeks - 6 months $(36.7 \%)$ or $7-12$ months $(32.5 \%)$. Almost all (98\%) were from a black African population group, mainly Zulu, Swati and Tswana. The inclusion criteria for the postnatal study were that the participant attended the clinic, was HIV positive, was 18 years of age and older, and had an infant less than 12 months old. Postnatal women were recruited by systematic sampling (every consecutive patient over a period of 2 months) from 48 primary care clinics and community health centres (of in total 74 clinics) in all 6 sub-districts of Nkangala district in Mpumalanga province. In all the 48 prevention of mother-to-child transmission (PMTCT) service points in the study area, every consecutive HIV-positive mother was invited to participate in the study through referrals by health care providers. These individuals were asked to inform HIV-positive mothers about the study when the mothers came to clinic visits, and to encourage them to volunteer. Trained interviewers conducted interviews with postnatal women at health care facilities, using structured questionnaires. The questionnaire was translated into the local language, isiZulu. Informed consent was obtained from each participant before she was interviewed. Study approval was obtained from the Human Sciences Research Council ethics committee and health authorities (provincial, district, sub-district and clinic level).

\section{MEASURES}

The questionnaire included socio-demographic items, male involvement, HIV test disclosure, delivery and infant profile, infant HIV diagnosis, stigma, discrimination, postnatal depression, attendance of support groups, and social support.

Male involvement was assessed with one item, 'Did the father of the baby accompany you to the clinic when you received antenatal care?' Response options were 'yes' or 'no'.

Postnatal depression. The 10-question Edinburgh Postnatal Depression Scale (EPDS) is a valuable and efficient way of identifying patients at risk for 'perinatal' depression. ${ }^{19}$ The EPDS is easy to administer and has proved to be an effective screening tool. Mothers who score above 13 are likely to be suffering from a depressive illness of varying severity. ${ }^{20,21}$ The EPDS score should not override clinical judgment. A careful clinical assessment should be carried out to confirm the diagnosis. The scale indicates how the mother has felt during the previous week. It has specificity and sensitivity greater than $76 \%,{ }^{22}$ has been validated antenatally and postnatally, ${ }^{20}$ and has been validated in a black South African population. ${ }^{23}$ The EPDS consists of 10-selfreported items, each response rated 0 - 3 based on severity, and summed to yield the total score $(0-30)$. The scale has items related to anxiety and depressive symptoms such as anhedonia, anxiety, tearfulness, helplessness and motivation. The EPDS scale does not rely on somatic symptoms, which is common in postpartum women irrespective of depression. Research has supported the construct validity of an intervieweradministered isiXhosa version of the EPDS for use in South Africa. ${ }^{24}$ In South Africa there have been two validation studies of the EPDS in community samples. The first found an optimal threshold of 11/12, or 12 and above, for women in the postnatal period. ${ }^{25}$ The second found that a threshold of $13 / 14$, or 14 and above, was optimal for classifying 'probable' cases of depression. ${ }^{25}$ The present study uses the threshold of 14 as a basis for interpretation. ${ }^{5}$ Cronbach's alpha for EPDS in this sample was 0.84 .

HIV/AIDS discrimination experiences. To assess AIDS-related discrimination, we asked participants if they had experienced seven discrimination-related events. All items referred to discrimination experiences related to their HIV-positive status, e.g. 'Have you experienced discrimination because of HIV?' Each item was responded to dichotomously, yes or no; scale scores represent the sum total of endorsed items, range $0-7{ }^{26}$ The Cronbach's alpha of this 7-item scale was 0.75 . In addition, three items on discrimination experiences with health care providers were included. To assess exposure to discrimination experiences with the health care provider, interviewees were prompted with the following: 'People with HIV often sense discrimination from health care providers in subtle ways. Has anyone in the health care system ever done any of the following to you?' e.g. 'Has anyone in the health care system ever exhibited hostility or a lack of respect toward you?' Each item was responded to dichotomously, yes or no; scale scores represent the sum total of endorsed items, range $0-3$. The Cronbach's alpha of this 3 -item sub-scale was 0.83 . 
Internalised AIDS stigma. We used the 7-item internalised AIDS-related stigma scale for people infected with HIV. ${ }^{27}$ Items reflected self-defacing beliefs and negative perceptions of people living with HIV/ AIDS, e.g. 'It is difficult to tell other people about my HIV infection.' Response options ranged from 1 = strongly agree to $4=$ strongly disagree. The Cronbach's alpha of this 7 -item scale was 0.88 .

Social support. Three items were drawn from the Social Support Questionnaire to assess perceived social support. ${ }^{26}$ The items were selected to reflect perceived tangible and emotional support. The four response options ranged from 'completely true' to 'completely false'; scale scores represent the sum total of endorsed items, range 3 - 12. The Cronbach's alpha of this 3 -item scale was 0.61 .

In addition, three individual items were used to assess social support. Two items referred to support during pregnancy ('Saw a traditional birth attendent during pregnancy' and 'Father of baby accompanied to antenatal care'), and one item assessed the attendance of a support group. Response options were 'yes' or 'no'.

Alcohol use was assessed with one item, 'Did you ever drink alcohol (beer, wine, home-brewed beer or spirits) in the past month?' Response options were 'Yes' or ' $N o$ '.

\section{DATA ANALYSIS}

The Statistical Package for Social Sciences (SPSS version 18.0 for Windows; SPSS Inc., Chicago, IL, USA) was used for data analyses. Descriptive data on the total sample were first examined. Postnatal women were then classified as having depressed mood or not, based on a score greater than or equal to 14 on the EPDS. Significantly skewed variables such as discrimination experiences were transformed using the formula $\log _{10}$ $(x+1)$. Bivariate analysis and multivariable logistic regressions were used to investigate associations between the socio-demographic, stressor, risk behaviour and social support variables and depressed mood. Unconditional logistic regression was then performed including the variables that had a significant $(p<0.05)$ bivariate relationship with EPDS. Associations were considered significant at $p<0.05$.

\section{RESULTS SOCIO-DEMOGRAPHIC CHARACTERISTICS}

Of the 615 women invited to participate in the study, 8 declined, resulting in a total sample of 607 participants (response rate $98.7 \%$ ). The mean age of the women was 28.5 (standard deviation (SD) 5.8) years, with a range of 18 - 51 years. One hundred and eighty-seven $(30.8 \%)$ of the participants had an infant aged $1-10$ weeks, 223 $(36.7 \%)$ an infant aged 11 weeks - 6 months and 197 (32.5\%) an infant aged 7 - 12 months. Thirty-five per cent had grade 12 or higher formal education, $53.6 \%$ grade 8 - 11 education, and $11.4 \%$ grade 7 or less education. Most postnatal women (69.6\%) had never been married, $28.4 \%$ were married or cohabitating and $2 \%$ were separated, divorced or widowed. Almost all came from a black African population group $(98.3 \%)$, with the main ethnic groups being Ndebele (27.8\%), Northern Sotho
(26.8\%) and Zulu (26.0\%). Economically, few mothers were employed $(11.4 \%)$ or receiving money from their partner $(23.2 \%)$ or family $(9.6 \%)$, while most received a child care support grant (66.4\%) and/or disability grant (3\%).

\section{PREVALENCE AND CORRELATES OF DEPRESSED MOOD}

Overall, $45.1 \%$ of women reported depressed mood in the postnatal period. Bivariate comparisons are presented in Table I. Having an HIV-positive sexual partner, no alcohol use in the past month, having been diagnosed with a sexually transmitted infection (STI) (other than HIV) in the past 12 months, inconsistent condom use with the primary partner, internalised stigma, discrimination experiences, lack of social support, and the baby's father not accompanying the woman to antenatal care were all found to be associated with depressed mood. Results from multivariable logistic regression are presented in Table II. In multivariable analysis, having been diagnosed with an STI (other than HIV) in the past 12 months, internalised stigma, discrimination experiences and lack of social support were associated with depressed mood.

\section{DISCUSSION}

Overall, $45.1 \%$ of women reported depressed mood in the postnatal period in the present study compared with $42.2 \%$ found in the study conducted by Hartley et al. ${ }^{5}$ in Cape Town and 54\% meeting DSM-IV criteria for depression among urban primary clinic attendees in Zimbabwe. $^{28}$

The study found that the strongest predictors of depressed mood among postnatal women were having had an STI in the past 12 months, internalised stigma, discrimination experiences and lack of social support. In a large Canadian community study STIs among women also increased the risk of depression. ${ }^{29}$ Diagnosis with an STI may contribute to the development of depression. ${ }^{29}$ Further, in previous studies it was also found that discrimination experiences were common and internalised AIDS stigma was prevalent among people living with HIVIAIDS. ${ }^{26}$ The results of the current study show a significant relationship between internalised stigma and depressed mood, and these results concurs with the study conducted by Ross et al., ${ }^{4}$ which found self-esteem to be the most powerful predictor of depressive symptoms among HIV-positive postpartum women and Wight's ${ }^{30}$ finding that internalised stigma is related to the development of depressive symptoms. Social support was found to be a factor buffering against postnatal depression. In the multivariate analysis, lack of social support remained significantly associated with depressed mood, and this finding concurs with other studies. $^{5,14,31,32}$

Having an unintended unplanned pregnancy, the infant being HIV positive and preterm delivery were not associated with a depressed mood in the current study. Tomlinson et al. ${ }^{33}$ also found that having an unintended pregnancy was associated with a depressed mood. Alcohol use in the current study was not associated with depressed mood in multivariate analysis, although 


\begin{tabular}{|c|c|c|c|c|c|c|}
\hline \multirow[b]{2}{*}{ Socio-economic variables } & \multicolumn{2}{|c|}{ EPDS $<14(n=333)$} & \multicolumn{2}{|c|}{ EPDS $\geq 14(n=274)$} & \multirow[t]{2}{*}{$\begin{array}{l}\text { Unadjusted } \\
\text { OR }(95 \% \mathrm{CI})\end{array}$} & \multirow[t]{2}{*}{$p$-value } \\
\hline & $N$ or mean & $\%$ or SD & $N$ or mean & $\%$ or SD & & \\
\hline Age & 28.7 & 5.9 & 28.3 & 5.7 & $0.99(0.96-1.02)$ & 0.440 \\
\hline $\begin{array}{l}\text { Age of infant } \\
1-10 \text { weeks } \\
11 \text { weeks }-6 \text { months } \\
7-12 \text { months }\end{array}$ & $\begin{array}{l}85 \\
110 \\
102\end{array}$ & $\begin{array}{l}51.2 \\
53.1 \\
56.0\end{array}$ & $\begin{array}{l}81 \\
97 \\
80\end{array}$ & $\begin{array}{l}48.8 \\
46.9 \\
44.0\end{array}$ & $\begin{array}{l}1.00 \\
0.97(0.66-1.43) \\
0.87(0.58-1.31)\end{array}$ & $\begin{array}{l}0.874 \\
0.506\end{array}$ \\
\hline $\begin{array}{l}\text { Education } \\
\text { Grade } 0-7 \\
\text { Grade } 8-11 \\
\text { Grade } 12+\end{array}$ & $\begin{array}{l}32 \\
183 \\
116\end{array}$ & $\begin{array}{l}46.4 \\
56.5 \\
54.7\end{array}$ & $\begin{array}{l}37 \\
141 \\
91\end{array}$ & $\begin{array}{l}53.6 \\
43.5 \\
45.3\end{array}$ & $\begin{array}{l}1.00 \\
0.67(0.40-1.12) \\
0.72(0.42-1.23)\end{array}$ & $\begin{array}{l}0.127 \\
0.229\end{array}$ \\
\hline $\begin{array}{l}\text { Single } \\
\text { Married/cohabitating } \\
\text { Separated/divorced/widowed }\end{array}$ & $\begin{array}{l}232 \\
89 \\
10\end{array}$ & $\begin{array}{l}55.4 \\
52.0 \\
83.3\end{array}$ & $\begin{array}{l}187 \\
82 \\
2\end{array}$ & $\begin{array}{l}44.6 \\
48.0 \\
16.7\end{array}$ & $\begin{array}{l}1.00 \\
1.14(0.80-1.63) \\
0.25(0.05-1.15)\end{array}$ & $\begin{array}{l}0.462 \\
0.074\end{array}$ \\
\hline Number of (own) children & 2.2 & 1.2 & 2.2 & 1.6 & $0.98(0.85-1.13)$ & 0.784 \\
\hline $\begin{array}{l}\text { Mother employed } \\
\text { Mother receives child care grant } \\
\text { Mother receives money from partner } \\
\text { Mother receives money from family }\end{array}$ & $\begin{array}{l}44 \\
224 \\
84 \\
25\end{array}$ & $\begin{array}{l}63.8 \\
55.6 \\
59.6 \\
43.1\end{array}$ & $\begin{array}{l}25 \\
179 \\
57 \\
33\end{array}$ & $\begin{array}{l}36.2 \\
44.4 \\
40.4 \\
56.9\end{array}$ & $\begin{array}{l}1.00 \\
0.95(0.64-1.39) \\
0.80(0.53-1.21) \\
1.57(0.86-2.85)\end{array}$ & $\begin{array}{l}0.785 \\
0.288 \\
0.140\end{array}$ \\
\hline \multicolumn{7}{|l|}{ Health status and reproductive health } \\
\hline CD4 cell count $<200$ cells $/ \mu$ l & 68 & 56.7 & 52 & 43.3 & $0.77(0.51-1.18)$ & 0.235 \\
\hline $\begin{array}{l}\text { Had STI (other than HIV) in the past } \\
12 \text { months }\end{array}$ & 49 & 34.8 & 92 & 25.6 & $2.66(1.80-3.91)$ & 0.000 \\
\hline Alcohol use in past month & 29 & 74.4 & 10 & 25.6 & $0.40(0.19-0.84)$ & 0.016 \\
\hline Current baby unintended & 186 & 51.5 & 175 & 48.5 & $1.33(0.95-1.88)$ & 0.102 \\
\hline Preterm (v. term) delivery) & 31 & 63.3 & 18 & 36.7 & $0.68(0.37-1.24)$ & 0.209 \\
\hline Baby had hospital admission & 75 & 56.0 & 59 & 44.0 & $0.80(0.55-1.16)$ & 0.234 \\
\hline Infant HIV positive & 9 & 56.3 & 7 & 43.8 & $0.94(0.35-2.57)$ & 0.910 \\
\hline \multicolumn{7}{|l|}{$\begin{array}{l}\text { Sexual behaviour and partner } \\
\text { characteristics }\end{array}$} \\
\hline Main sexual partner HIV positive & 105 & 45.1 & 128 & 54.9 & $1.48(1.04-2.11)$ & 0.029 \\
\hline $\begin{array}{l}\text { Intimate partner violence in past } \\
12 \text { months }\end{array}$ & 16 & 44.4 & 20 & 55.6 & $1.49(0.75-2.93)$ & 0.253 \\
\hline $\begin{array}{l}\text { More than one sexual partner in past } \\
12 \text { months }\end{array}$ & 34 & 53.1 & 30 & 46.9 & $0.98(0.58-1.65)$ & 0.932 \\
\hline Casual partner in past 3 months & 23 & 48.9 & 24 & 51.1 & $1.19(0.66-2.17)$ & 0.562 \\
\hline $\begin{array}{l}\text { Inconsistent condom use with primary } \\
\text { partner }\end{array}$ & 166 & 49.1 & 172 & 50.9 & $1.47(1.04-2.07)$ & 0.030 \\
\hline \multicolumn{7}{|l|}{ Discrimination and stigma } \\
\hline Internalised stigma score (range 7 - 28) & 16.0 & 4.2 & 18.6 & 5.2 & $1.13(1.08-1.17)$ & 0.000 \\
\hline $\begin{array}{l}\text { Discrimination experiences score } \\
\text { (range } 0-7 \text { ) }\end{array}$ & 0.9 & 1.3 & 1.4 & 1.7 & $1.28(1.13-1.44)$ & 0.000 \\
\hline \multicolumn{7}{|l|}{ Social support } \\
\hline Social support score (range 3 - 12) & 8.2 & 1.7 & 7.3 & 2.0 & $0.77(0.70-0.84)$ & 0.000 \\
\hline $\begin{array}{l}\text { Saw a traditional birth attendant during } \\
\text { pregnancy }\end{array}$ & 68 & 45.6 & 81 & 54.4 & $1.35(0.94-1.93)$ & 0.105 \\
\hline $\begin{array}{l}\text { Father of baby accompanied to } \\
\text { antenatal care }\end{array}$ & 77 & 67.0 & 38 & 33.0 & $0.51(0.34-0.78)$ & 0.002 \\
\hline Attended support group & 62 & 51.2 & 59 & 48.8 & $1.20(0.81-1.80)$ & 0.368 \\
\hline
\end{tabular}

it reached significance in the bivariate analysis. This concurs with the results of Hartley et al. ${ }^{5}$ Other factors that were significantly associated with a depressed mood in the current study in bivariate analysis included having an HIV-positive partner and inconsistent condom use with the primary partner. This seems to indicate that partner dynamics may influence the wellbeing of HIVinfected mothers. 
Health status, sexual behaviour and partner characteristics

Adjusted

Had STI (other than HIV) in the past 12 months

OR $(95 \% \mathrm{Cl})^{\star \dagger}$

$p$-value

Alcohol use in past month

$2.22(1.21-4.04)$

0.010

$0.43(0.16-1.17)$

Main sexual partner HIV positive

$1.63(0.97-2.71)$

Inconsistent condom use with primary partner

$1.51(0.88-2.59)$

0.140

Discrimination and stigma

Discrimination experiences score (range 0 - 7)

$1.22(1.03-1.46)$

0.023

Internalised stigma score (range 7 - 28)

$1.12(1.05-1.19)$

0.000

Social support

Social support score (range 3 - 12)

$0.86(0.74-0.99)$

Father accompanied to antenatal care

$0.55(0.28-1.08)$

0.084

*Using 'enter' logistic regression selection of variables

${ }^{\dagger}$ Hosmer and Lemeshow chi-square 14.55, df 8, 0.536; Cox and Snell $R^{2} 0.20$; Nagelkerke $R^{2} 0.27$

$\mathrm{OR}=$ odds ratio; $\mathrm{Cl}=$ confidence interval.

\section{CONCLUSION}

The study found a high prevalence of postnatal depression symptoms among HIV-positive women, and that several factors were associated with depression. The development of interventions can specifically address such factors, i.e. encouraging partner involvement campaigns, and training health workers to address their own and mothers' stigma towards HIV. It is feasible to screen for postnatal depression in primary care clinics using peer counsellors. We recommend that screening for postnatal depression and access to mental health interventions should be part of routine antenatal care for all women.

Acknowledgement. This publication was supported by Cooperative Agreement Number U2G/PS000570 from the Centers for Disease Control and Prevention (CDC). Its contents are solely the responsibility of the authors and do not necessarily represent the official views of the CDC.

\section{REFERENCES}

1. Sawyer A, Ayers S, Smith, H. Pre- and postnatal psychological wellbeing in Africa: A systematic review. J Affect Disord 2010;123:17-29.

2. Robertson $E$, Grace $S$, Wallington $M D$, et al. Antenatal risk factors for postpartum depression: a synthesis of recent literature. Gen Hosp Psychiatry 2004;26:289-295.

3. Cooper $P$, Tomlinson M, Swartz L, et al. Postpartum depression and the motherinfant relationship in a South African peri-urban settlement. $\mathrm{Br} \mathrm{J}$ Psychiatry 1999; $175: 554-558$

4. Ross R, Sawatphanit W, Mizuno M, et al. Depressive symptoms among HIV-positive postpartum women in Thailand. Arch Psychiatr Nurs 2011;25(1):36-42.

5. Hartley C, Pretorius K, Mohamed A, et al. Maternal postpartum depression and infant social withdrawal among human immunodeficiency virus (HIV) positive mother-infant dyads. Psychol Health Med 2010;15(3):278-287

6. Cook JA, Grey D, Burke J, et al. Depressive symptoms and AIDS-related mortality among a multisite cohort of HIV positive women. Am J Public Health 2004:94(7):1133-1140.

7. Olley BO, Seedat S, Nei DG, et al. Predictors of major depression in recently diagnosed patients with HIVIAIDS in South Africa. AIDS Patient Care STDs 2004;18(8):481-487.

8. Antelman G, Kaaya S, Wei R, et al. Depressive symptoms increase risk of HIV disease progression and mortality among women in Tanzania. J Acquir Immune Defic Syndr 2007;44(4):470-477

9. Adewuya AO, Fatoye FO, Ola BA, et al. Sociodemographic and obstetric risk factors for postpartum depressive symptoms in Nigerian women. J Psychiatr Pract 2005;11(5):353-358.
10. Ramchandani $P$, Richter $L$, Stein $A$, et al. Predictors of postnatal depression in an urban South African cohort. J Affect Disord 2009;113:279-284.

11. Milgrom J, Gemmill AW, Bilszta JL, et al. Antenatal risk factors for postnatal depression: A large prospective study. J Affect Disord 2008;108:147-157.

12. Ingram $\mathrm{D}$, Hutchinson $\mathrm{S}$. Double binds and the reproductive and mothering experiences of HIV-positive women. Qual Health Res 2000;10(1):117-132.

13. Prachakul W, Grant JS, Keltner NL. Relationships among functional social Support, HIV-related stigma, social problem solving, and depressive symptoms in people living with HIV: A Pilot Study. JANAC Association of Nurses in AIDS Care 2007;18(6):67-76.

14. Bennetts A, Shaffer N, Manopaiboon C, et al. Determinants of depression and HIVrelated worry among HIV-positive women who have recently given birth, Bangkok, Thailand. Soc Sci Med 1999;49(6):737-749

15. Nkangala District Municipality. Integrated development plan 2011-16. www. nkangaladm.org.za/.../200-idp-part-one-background-and-intro (accessed 20 October 2011).

16. Department of Health and Social Services, Mpumalanga (2008) PMTCT report. Nelspruit: Department of Health, 2008.

17. Health Systems Trust. Health and related indicators. www.hst.org.za/uploads/files/ chap15_07.pdf (accessed 18 October 2011).

18. Department of Health. National antenatal sentinel HIV and syphilis prevalence survey in South Africa, 2009. Pretoria: Department of Health, 2010.

19. Cox JL, Holden JM, Sagovsky R. Detection of postnatal depression: Development of the 10-item Edinburgh Postnatal Depression scale. Br J Psychiatry 1987;150:782786.

20. Heron J, O'Conner TG, Evans J, et al. The course of anxiety and depression through pregnancy and the postpartum in a community sample. J Affect Disord 2004:80:65-73.

21. Rochat TJ, Richter LM, Doll HA, et al. Depression among pregnant rural South African women undergoing HIV testing. JAMA 2006;295(12):1376-1378.

22. Evans J, Heron J, Francomb H, et al. Cohort study of depressed mood during pregnancy and after childbirth. BMJ 2001;323:257-260.

23. De Bruin GP, Swartz L, Tomlinson M, et al. The factor structure of the Edinburgh Postnatal Depression Scale in South African peri-urban settlement. S Afr J Psychol 2004:34:113-121.

24. Lawrie TA, Hofmeyr GJ, de Jager M, et al. Validation of the Edinburgh Postnatal Depression scale on a cohort of South African women. S Afr Med J 1998;88:13401344.

25. Rochat T, Tomlinson M, Newell M, et al., Depression among pregnant women testing for HIV in rural South Africa: Implications for VCT. 9th International AIDS Impact Conference; Botswana, 2009.

26. Simbayi LC, Kalichman S, Strebel A, et al. Internalized stigma, discrimination, and depression among men and women living with HIVIAIDS in Cape Town, South Africa. Soc Sci Med 2007;64:1823-1831.

27. Kalichman SC, Simbayi LC, Cloete A, Mthembuc PP, Mkhontac RN, Ginindza T. Measuring AIDS stigmas in people living with HIVIAIDS: The Internalized AIDSRelated Stigma Scale. AIDS Care 2009;21(1):87-93.

28. Chibanda D, Mangezi W, Tshimanga M, et al. Postnatal depression by HIV status among women in Zimbabwe. J Womens Health 2010;19(11):2071-2077.

29. Chen Y, Wu J, Yi Q, Huang G, Wong T. Depression associated with sexually transmitted infection in Canada. Sex Transm Infect 2008;84(7):535-540.

30. Wight RG. Precursive depression among HIV infected AIDS caregivers over time. Soc Sci Med 2000:51:759-770.

31. Howell EA, Mora PA, DiBonaventura MD. Modifiable factors associated with changes in postpartum depressive symptoms. Arch Womens Ment Health 2009;12:113-120.

32. Gao Y, MacDonald D, Collins KD, Alaghehbandan R, Chen Y. Role of social support in the relationship between sexually transmitted infection and depression among young women in Canada. J Epidemiol 2010;20(4):313-318.

33. Tomlinson M, Swartz L, Cooper P, et al. Social factors and postpartum depression in Khayelitsha, Cape Town. S Afr J Psychol 2004;34:409-420 